\title{
TRPA1 Is Expressed in Central But Not in Peripheral Glia
}

\section{Vittorio Vellani' ${ }^{1}$, Carolina Gomis-Perez ${ }^{2}$, Marcello Pinti ${ }^{3}$, Massimiliano Prandini' ${ }^{1}$ Giorgia Pavesi ${ }^{1}$, Chiara Giacomoni ${ }^{4}$, Marco Caprini2 ${ }^{2}$}

${ }^{1}$ Department of Biomedical Metabolic and Neural Sciences, University of Modena and Reggio, Modena, Italy

${ }^{2}$ Department of Pharmacy and Biotechnology, University of Bologna, Bologna, Italy

${ }^{3}$ Department of Life Sciences, University of Modena and Reggio, Modena, Italy

${ }^{4}$ Department of Economy and Technology, University of San Marino, Città di San Marino, Republic of San Marino

Email:vvellani@unimore.it

How to cite this paper: Vellani, V., Gomis-Perez, C., Pinti, M., Prandini, M., Pavesi, G., Giacomoni, C. and Caprini, M. (2016) TRPA1 Is Expressed in Central But Not in Peripheral Glia. J. Biomedical Science and Engineering, 9, 515-531. http://dx.doi.org/10.4236/jbise.2016.911046

Received: August 26, 2016

Accepted: October 23, 2016

Published: October 26, 2016

Copyright $\odot 2016$ by authors and Scientific Research Publishing Inc. This work is licensed under the Creative Commons Attribution International License (CC BY 4.0).

http://creativecommons.org/licenses/by/4.0/ (c) (i) Open Access

\begin{abstract}
TRPA1 are cation channels expressed in sensory neurons and in several other cell types. This channel is specifically activated by ally isothiocyanate (AITC), the pungent component of mustard oil, as well as by other electrophilic compounds. Although TRPA1 expression in central glia has been reported, its subcellular localization and its expression in peripheral glia have not been investigated before. In this paper we report the molecular and functional expression of TRPA1 in rat cortical astrocytes. Real-time RT-PCR identified low but significant amounts of TRPA1 mRNA in cortical astrocytes while no signal was seen in peripheral glia isolated from dorsal root ganglia (DRG) or in a glial cell line (DITNC-1). Calcium imaging showed AITC-induced signals in astrocytes while no response in peripheral glia. AITC induced calcium signals in astrocytes in the presence and in the absence of extracellular calcium, suggesting an intracellular localization of TRPA1 channels. Whole cell electrophysiological recordings were performed in astrocytes, in peripheral glia and in DITNC-1 cells transfected with TRPA1 during AITC application. In TRPA1-transfected DITNC-1 cells typical TRPA1 currents were recorded with a reversal potential near $0 \mathrm{mV}$, consistent with the opening of a non-selective cation channel. No such currents were recorded in untransfected DITNC-1 cells, in astrocytes and in peripheral glial cells, where even high concentrations of AITC (up to $10 \mathrm{mM}$ ) induced no significant outward current. In astrocytes AITC transiently induced an outward rectifying current with the reversal potential near $-90 \mathrm{mV}$, consistent with $\mathrm{K}$ channel activation, likely activated by intracellular release of calcium. Our results suggest that TRPA1 channels are molecularly and functionally expressed in calcium-containing organelles of rat cortical astrocytes, with no expression in the plasma membrane.
\end{abstract}




\section{Keywords}

Astrocytes, Intracellular TRPA1, DITNC-1, Ensheathing Schwann Cells

\section{Introduction}

Transient receptor potential ankirin-1 (TRPA1) is an ion channel member of the transient receptor potential family [1] [2]. The intracellular aminoterminal contains a remarkable number (up to 18) of predicted ankyrin repeats, while most other TRPs have zero to 8 ankyrin repeats [3]. This channel, formerly termed ANKTM1, was first identified as a transformation-sensitive RNA transcript in human fibroblasts [4], is a distant family member of TRP channels with sensitivity to cooling, and it displays very little amino acid similarity and much lower activation temperature (around $17^{\circ} \mathrm{C}$ ) compared to the cold and menthol receptor TRPM8 [5]. In the peripheral nervous system, TRPA1 is found in a population of sensory neurons distinct from those expressing TRPM8 [6], and almost exclusively in nociceptive afferents, largely colocalized with TRPV1, the capsaicin receptor [7] [8], and with the neuropeptides substance P and CGRP [5].

TRPA1 channels, as well as by intense cooling, can be gated by structurally diverse reactive electrophilic compounds capable of causing covalent modification of key $\mathrm{N}$ terminal cysteine residues [9] [10] thereby forming covalent adducts with thiol groups. The canonical selective activators of TRPA1, allyl isothiocyanate (AITC), is also known as mustard oil, the pungent component contained in foods such as mustard and wasabi. Other exogenous compounds (cinnamaldehyde, tear gasses, nicotin, formalin, plantderived cannabinoids [6]) activate wild-type TRPA1 channels when expressed in native and heterologous systems by the covalently modification within the amino terminal cytoplasmic domain of the channel [9] [10] [11]. As expected, cysteine-to-serine mutant TRPA1 channels are not activated by AITC [9].

Detected in several areas of the murine central nervous system (CNS) [12], interestingly TRPA1 has been recently localized in hyppocampal astrocytes, where it is functionally expressed in the plasma membrane, where it participates in regulation of basal intracellular $\mathrm{Ca}^{2+}$, contributing to NMDA receptor-dependent long term potentiation via $\mathrm{D}$-serine release [13] and in other modulatory functions [14]. TRPA1 has also been detected in astrocytes in the brainstem (specifically, in the rat trigeminal caudal nucleus) with upregulation during experimental inflammation of the temporomandibular joint [15].

Because of its ligand sensitivity and modulation properties, TRPA1 has been proposed to be a chemical sensor in the nervous system (both peripheral and central), with relevant tasks in neurons as well as in glial cells, in addition to roles also in other systems [16] [17].

The present study provides novel information on TRPA1 in glial cells by investigating its molecular and functional expression in rat cortical astrocytes, in glial cells isolated from dorsal root ganglia (DRG) and in DI TNC1 cells [18]. 


\section{Results}

\subsection{Astrocytes Calcium Responses to AITC}

TRPA1 is a non-selective cation channel with good permeability to calcium. We examined whether the agonist allyl isothiocyanate, also called mustard oil (MO), stimulated cultured astrocytes to produce changes in intracellular free calcium concentration $\left(\left[\mathrm{Ca}^{2+}\right]_{\mathrm{i}}\right)$ as an indication of TRPA1 activation. Although with low affinity, AITC evoked a visible increase in $\left[\mathrm{Ca}^{2+}\right]_{\mathrm{i}}$ in astrocytes, with a little variation in different cultures (percentage of responsive cells ranged between 80 and 100\%). Occurrence of non-responsive cultures was seen only once in 21 cultures tested. Responses to AITC occurred both in the presence and absence of external calcium (Figure 1(a)) and full dose-response studies were carried out measuring responses induced by AITC in both conditions (Figure 1(b)). Because of the gating mechanism, TRPA1 shows large adaptation to AITC, with slow and incomplete recovery of sensitivity, therefore only the first concentration of AITC tested in each coverslip was considered. Amplitude of response was normalized to fluorescence in the presence of ionomycin $(10 \mu \mathrm{M}$ applied in $30 \mathrm{mM}$ calcium) measured at the end of the recording. Presence or absence of extracellular calcium did not affect AITC-induced $\left[\mathrm{Ca}^{2+}\right]_{\mathrm{i}}$ increase. Calcium signals were produced by AITC application in DRG cultures in a subpopulation of neurons, as previously shown [19] [20] but no response at all was ever seen in non-neuronal cells (not shown) in a large number of recordings (more than 30 coverslips). $10 \mathrm{mM}$ AITC did not produce signals in DRG non-neuronal cells cultured both in the presence and in the absence of ARA-c, nerve growth factor (NGF, $100 \mathrm{ng} / \mathrm{ml}$ ), glia-derived neurotropic factor (GDNF, $50 \mathrm{ng} / \mathrm{ml})$, neurturin $(50 \mathrm{ng} / \mathrm{ml})$ and a mixture of NGF and GDNF at the same concentrations (not shown).

\subsection{TRPA1 mRNA Is Expressed in Astrocytes}

The expression of TRPA1 mRNA was analysed in sensory neurons, in central and peripheral glial cells, and in naive DT NC1 cells by real time PCR. DRG neurons isolated from neonatal rats were used as positive control. The relative expression data are reported in Figure 2. TRPA1 messenger, which was normalized to GAPDH levels, is clearly detectable in neuronal cells, as expected. In cultured peripheral glial cells (ensheathing Schwann cells and satellite cells) isolated from DRG ganglia, we did not detected any significant amplification of TRPA1. On the contrary, cortical astrocytes show a low, but consistent and clearly detectable expression of TRPA1 mRNA, which is about $2.7 \% \pm 1.1 \%$ of mRNA levels measured in DRG neuronal cells, where level of expression is very high. TRPA1 mRNA expression in DITNC-1 cells was undetectable, except in positive controls when transfection with TRPA1 plasmid had been performed (not shown).

\subsection{AITC Activates Potassium Channel Currents in Cultured Cortical Astrocytes}

Whole cell patch clamp experiments were performed to verify the presence of functional 


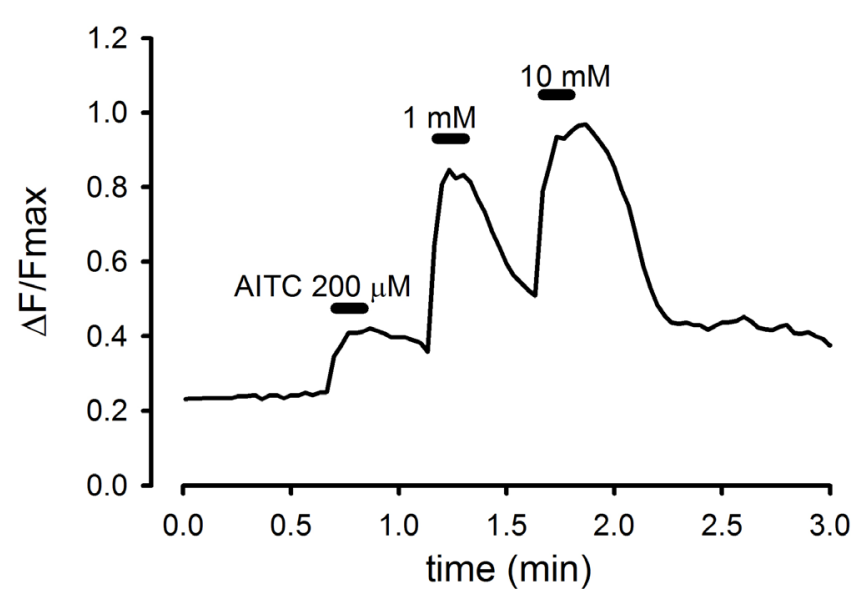

(a)

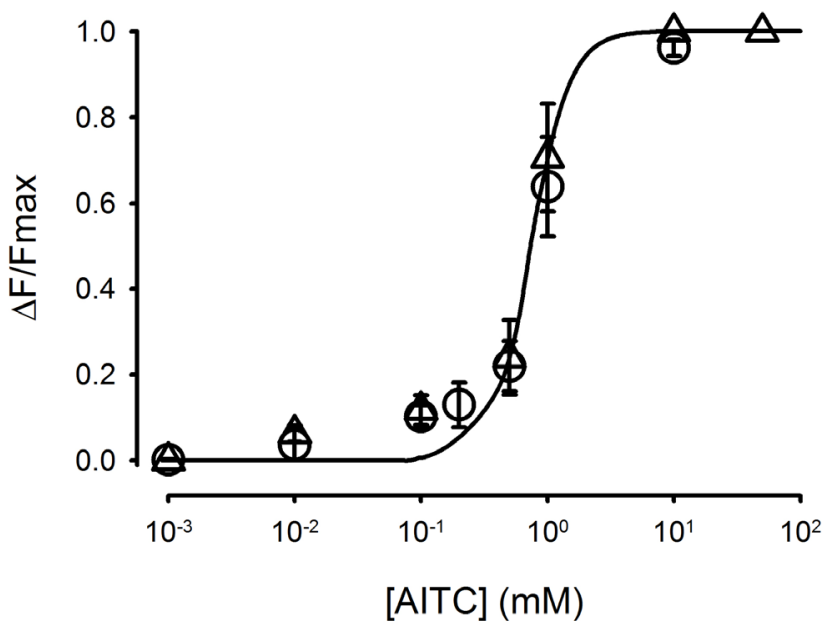

(b)

Figure 1. AITC generates calcium signals in astrocytes. (a) Response recorded from a single astrocyte to increasing concentrations of AITC in the absence of extracellular $\mathrm{Ca}^{2+}$, indicating AITC-induced release from internal stores. (b) Dose-response curve obtained in the presence (triangles) and in the absence (circles) of extracellular calcium. Each measurement was obtained by challenging a coverslip to a single $30 \mathrm{~s}$ application of AITC. Response amplitude was normalised to response to ionomycin applied in the presence of $30 \mathrm{mM}$ extracellular calcium, applied at the end of the experiment. Each datapoint represents an average of four to twelve independent coverslip readings. Each coverslip reading represents the average response of astrocytes present in the coverslip. Data were interpolated with the Hill equation. $K_{1 / 2}$ was $798 \mu$ M AITC in the absence and $737 \mu \mathrm{M}$ in the presence of extracellular calcium, and the Hill coefficient was 2.6 and 2.8 respectively. The graph shows the theoretical Hill curve for 0 calcium data. Error bars represent the standard error and are only plotted when they exceeded symbol size.

TRPA1 channel in the plasma membrane of cultured cortical astrocytes. Voltage clamp experiments were conducted by holding the membrane potential $(\mathrm{Vh})$ at $-60 \mathrm{mV}$ and stimulating the cells with a voltage step to $-120 \mathrm{mV}$ for $400 \mathrm{~ms}$ followed by a $500-\mathrm{ms}$ long depolarizing ramp to $+60 \mathrm{mV}$ (Figure $3(\mathrm{a})$ inset). Under these conditions only an outwardly rectifying $\mathrm{K}^{+}$current was elicited at potentials more positive than $-40 \mathrm{mV}$, as previously seen [21]. AITC mediated an increase in membrane conductance which 


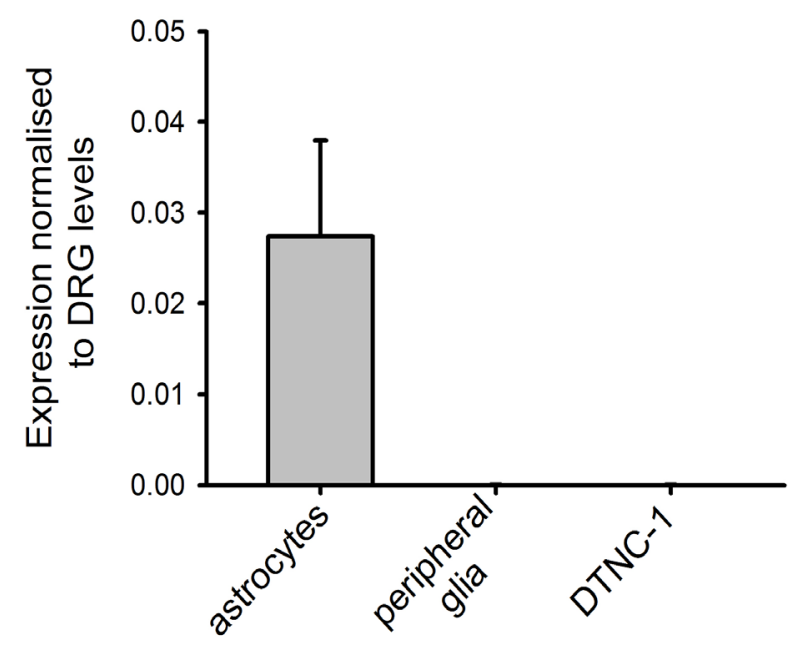

Figure 2. TRPA1 mRNA is expressed in central but not in peripheral glia. TRPA1 mRNA quantitation normalised to expression measured in DRG neurons. Significant signal was detected in astrocytes but not in non-neuronal cells isolated from DRG sensory neurons and in DITNC-1 cells ( $n=6$; error bars represent standard error of the mean).

was sustained and completely reversible (Figure 3(c) and Figure 3(d)), both spontaneously and after AITC wash out. The steady-state current-voltage relationship (I-V) of the AITC-induced current (Figure 3(b)) suggests that AITC increased the astroglial $\mathrm{K}^{+}$ conductance, as the zero-current potential shifted from $-37.9 \pm 2.5 \mathrm{mV}$ to $-73.2 \pm 5.9$ $\mathrm{mV}(\mathrm{n}=16)$, which is a value close to the equilibrium potential of $\mathrm{K}^{+}(\mathrm{EK})$ of about -91 $\mathrm{mV}$ expected in our experimental conditions.

The quantitative analysis (Figure 3(e)) indicated that AITC effect was statistically significant only in the positive range of membrane potentials $(\mathrm{p}<0.001)$. These results suggest that in cultured astroglial cells, even at very high concentration, AITC does not produce any activation of TRPAl cation channel, but instead causes an increase in $\mathrm{K}^{+}$ permeability.

It is well known that the activity of TRPA1 promotes an increase in intracellular $\mathrm{Ca}^{2+}$ [22]-[25] and that voltage-dependent $\mathrm{Ca}^{2+}$ conductances may [26] [27] or may not [28] be expressed in astrocytes. To address the possibility that the effect of AITC on $\mathrm{K}^{+}$ conductance was mediated by an increase in $\left[\mathrm{Ca}^{2+}\right]$ int caused by an influx from the plasma membrane, a set of experiments was performed by using $\mathrm{Ca}^{2+}$-free bath solution. Figure 4(a) and Figure 4(b) shows that the basal currents activated in the absence of extracellular $\mathrm{Ca}^{2+}$ before stimulation were not affected by extracellular $\mathrm{Ca}^{2+}$ removal. Subsequent exposure of astrocytes to AITC promoted and increase in membrane conductance at positive potentials that was comparable to that observed in the presence of extracellular $\mathrm{Ca}^{2+}$. The I-V plot of the AITC-mediated current illustrates that the current reversal potential was not significantly different from that measured in physiological $\mathrm{Ca}^{2+}$ (Figure 4(b)). The quantitative analysis denotes that the current density at 


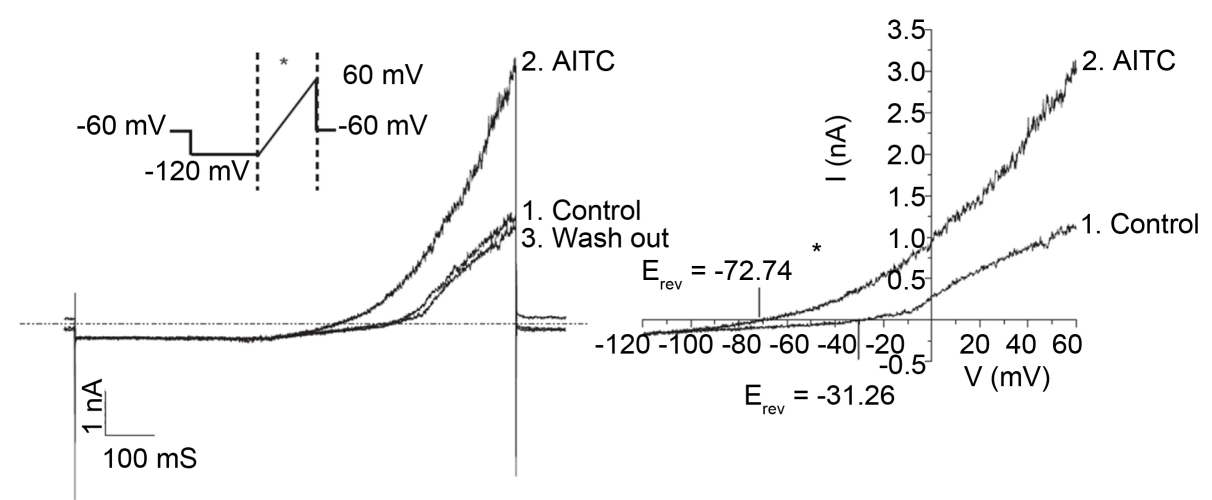

(a)

(b)

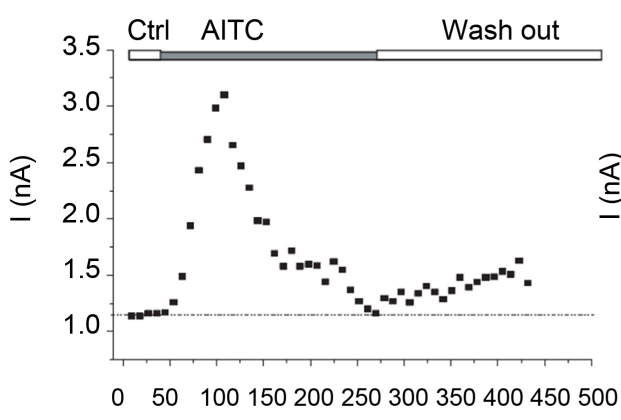

$\mathrm{t}(\mathrm{s})$

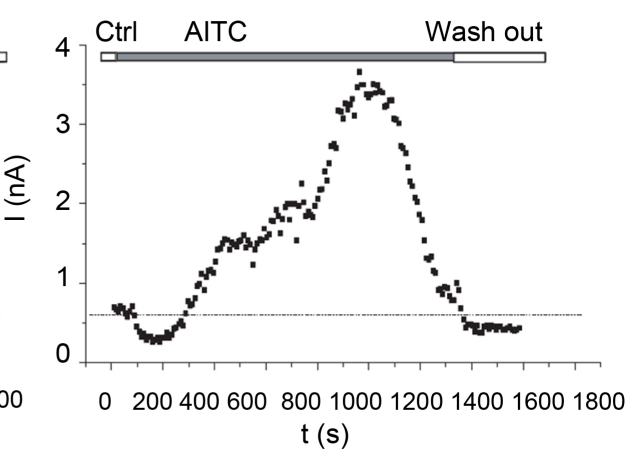

(d)

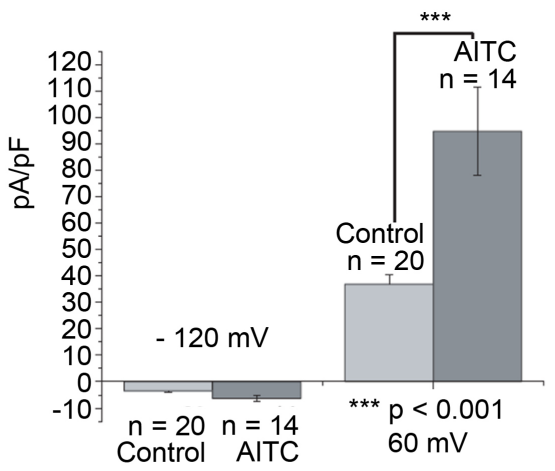

(e)

Figure 3. AITC activates potassium channel current in cultured cortical astrocytes. (a) Representative current traces activated from a holding potential ( $\mathrm{Vh}$ ) of $-60 \mathrm{mV}$ after ramp stimulation (inset). Upon exposure to $10 \mathrm{mM}$ AITC a large outward rectifying increase in membrane conductance in the whole range of ramp potential was observed. Note that upon washout of AITC the current returned to the level of the control trace (3). (b) The I-V curve of current traces to steady-state current levels before and after AITC exposure. AITC shifts Erev to much more negative potentials. (c), (d) Time-course of experiments in A-and B. Astrocytes exposed to 10 mM AITC showed in all cases a slowly developing and reversible large increase in outward current. In a minority of cases an initial inhibition of the basal outward current was observed immediately after AITC application, followed by a delayed but large increase (d). (e) Histogram of current densities at $-120 \mathrm{mV}$ and $60 \mathrm{mV}$ in the two conditions, the asterisks indicate $\mathrm{P}<0.001$, with ANOVA followed by Bonferroni's post-hoc test. 


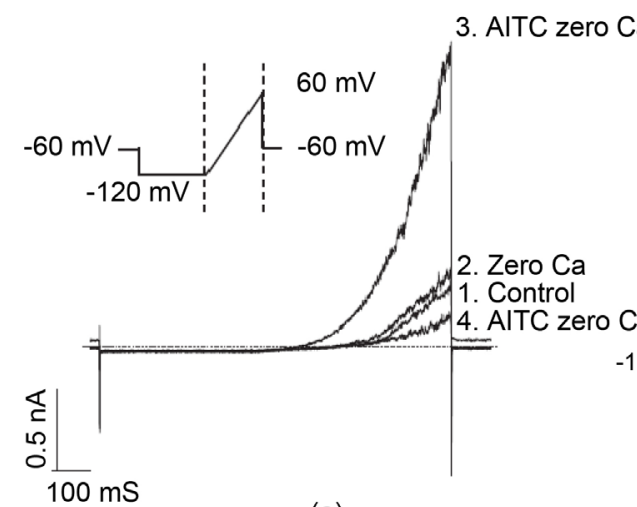

(a)

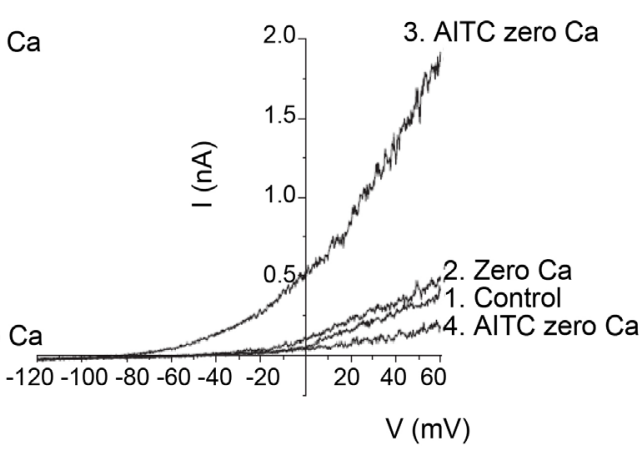

(b)

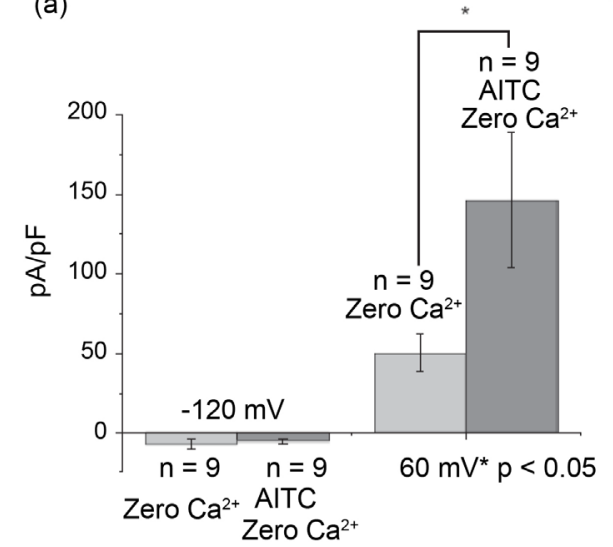

(c)

Figure 4. The outward rectifier current induced by AITC is not influenced by extracellular calcium in cultured cortical astrocytes. (a) Representative current traces activated by the same stimulation ramp shown in Figure 3. Upon exposure to $10 \mathrm{mM}$ AITC a large outward rectifying current is shown (3), rapidly followed by deactivation (4). Interestingly, this deactivation current was smaller than the control traces $(1,2)$. (b) The I-V curve of steady-state currents before and after AITC exposure. AITC shifts the Erev to more negative voltage potential compared to control conditions $(0 \mathrm{mV})$. (c) Histogram of current densities at $-120 \mathrm{mV}$ and $+60 \mathrm{mV}$ with and without AITC, the asterisk indicate $\mathrm{P}<0.05$, with ANOVA followed by Bonferroni's posthoc test. Only outward rectifier currents were significantly different.

both positive and negative potentials following the maximal activation by AITC was not different from that obtained in the presence of extracellular $\mathrm{Ca}^{2+}$ (Figure 4(c) and Figure 3(e)). Surprisingly, however, in the absence of extracellular $\mathrm{Ca}^{2+}$ prolonged exposure to AITC caused a diminution of the evoked current and an irreversible depression of basal conductance.

\subsection{AITC Does Not Have Any Effect of Electrical Properties on Peripheral Glia}

We next investigate whether AITC could cause similar effects on membrane currents in peripheral glial cells (satellite cells/ensheating Schwann cells) isolated from dorsal root ganglia. In our recording conditions, the peripheral glial cells showed very high membrane resistance, and the absence of any noticeable voltage-dependent currents when 
investigated with the ramp shown in Figure 5(a). AITC applied at the same concentration used in cortical astrocytes $(10 \mathrm{mM})$ did not evoke any significant change in membrane conductance $(n=5$, Figure $5(\mathrm{~b})$ ), even upon prolonged exposure $(10-15 \mathrm{~min})$. This result suggests that AITC does not cause aspecific effects on the plasma membrane, that the effect observed must be mediated by a secondary mechanism activated by AITC, causing the effect on astroglial $\mathrm{K}^{+}$conductance.

As a control, we recorded the effect of $10 \mathrm{mM}$ AITC on the glial cell line DITNC-1. This cell line does not express any endogenous TRPA1 (Figure 2). Patch clamp recordings were performed on naive DI TNC-(1) and on cells transiently transfected with recombinant TRPA1. As expected for a non selective cation channel, the AITC challenge caused, in transfected cells, a robust increase in membrane conductance. The current increase had an ohmic behavior (Figure 6(a)). The reversal potential of the AITC-induced current obtained by the I-V curve was substantially not far away from 0 $($ Erev $=-7.6)$, a result consistent with the presence of TRPA1 in the plasma membrane.

\section{Methods}

\subsection{Astrocytes Cell Culturing}

Primary cultures of pure cortical rat astrocytes were prepared as previously described [21]. Newborn Sprague Dawley rats were sacrificed under total anaesthesia according to Italian and European legislations, with protocols in agreement with the guidelines of the Committee for Research and Ethical Issues of IASP published in PAIN ${ }^{\circledR}, 16$ (1983) 109-110.27. Experimental work was also reviewed and approved by local institutional animal care and use committee. Briefly, after removing the meninges, the cerebral cortices of newborn up to 2-day-old pups (P0-P2) were mechanically dissociated and placed in cell culture flasks containing DMEM-glutamax medium supplemented with
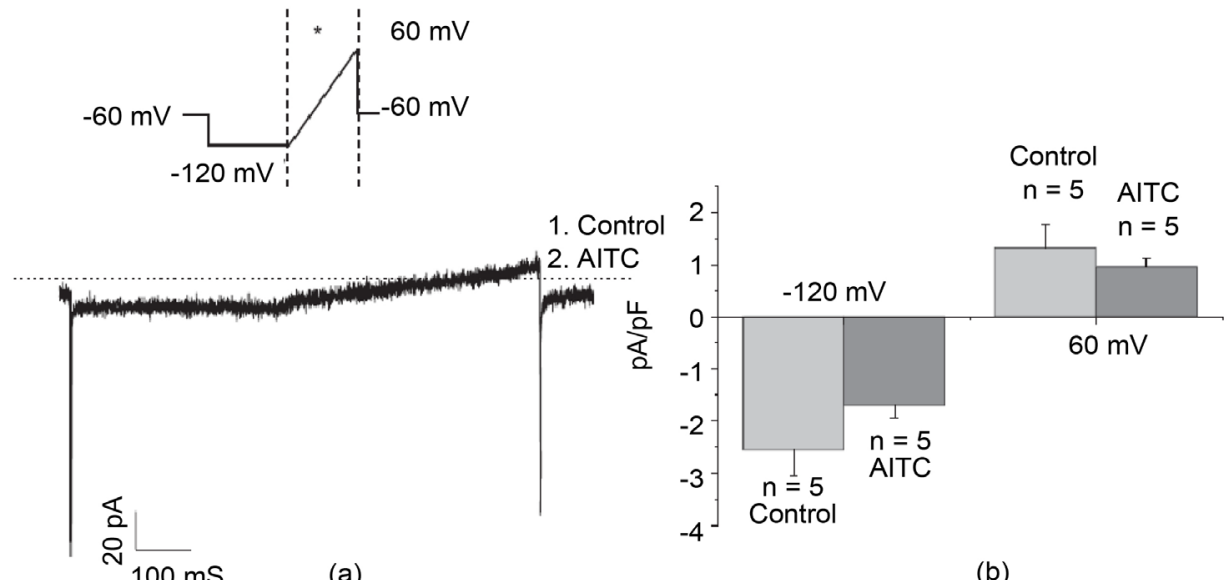

Figure 5. Absence of AITC-induced currents in peripheral glia. (a) Current development after ramp stimulus (inset) recorded in non-neuronal cells isolated from dorsal root ganglia. The AITC application did not produce any change in the control trace $(1,2)$. (b) The histogram of current densities at $-120 \mathrm{mV}$ and $60 \mathrm{mV}$ did not show any significant difference between control condition and after AITC exposure. 


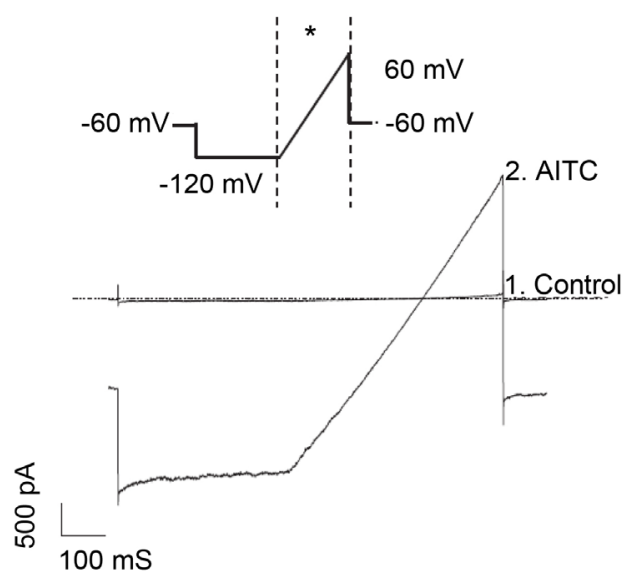

(a)

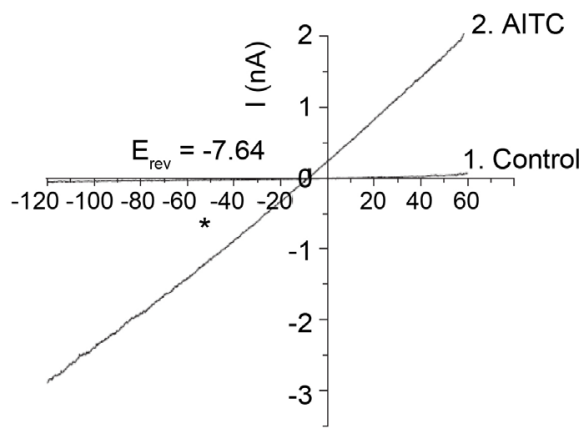

(b)

Figure 6. Positive control of the TRPA1 channel expressed in DI-TNC cells. (a) TRPA1 currents activated by AITC after ramp stimulation (inset). (b) The I-V relationship showed a large decrease in membrane resistance caused by AITC with Erev remaining near zero $\mathrm{mV}(-10 \mathrm{mV}$ in this recording), which is typical of TRPA1 channels.

$15 \%$ foetal bovine serum (FBS), $100 \mathrm{U} / \mathrm{ml}$ penicillin and $100 \mathrm{mg} / \mathrm{ml}$ streptomycin (all products purchased from Gibco-Invitrogen, Milan, Italy). Culture flasks were maintained in a humidified-atmosphere incubator at $37^{\circ} \mathrm{C}$ and $5 \% \mathrm{CO}_{2}$ for three to five weeks. The culturing medium was replaced every three days. Before changing the medium flasks were shaken for 5 minutes in order to detach microglial cells that seeded on top of the astrocyte monolayer. Immunostaining for the glial fibrillary acidic protein (GFAP) and the flat, polygonal morphological phenotype of the cultured cells indicated that more than $95 \%$ were type-1 cortical astrocytes [29].

\subsection{Sensory Neurons and Peripheral Glial Cells Culturing}

Sprague Dawley rats (2 - 3 weeks old) were sacrificed as decribed above. Dorsal root ganglia (DRGs) containing neuronal cell bodies and peripheral glial cells were carefully dissected removing perineurium and nerve branches, incubated for 1 hour at $37^{\circ} \mathrm{C}$ with $0.125 \%$ collagenase (Worthington, Freehold, NJ), and mechanically dissociated, plated onto flasks or Petri dishes pretreated with $10 \mu \mathrm{g} / \mathrm{ml}$ poly-L-lysine (Sigma, St. Louis, MO). For plating on glass also a treatment with $20 \mu \mathrm{g} / \mathrm{ml}$ laminin (Sigma, Milan, Italy) was necessary. Cells were cultured in DMEM containing $1 \%$ penicillin/streptomycin, $10 \%$ fetal bovine serum, $1 \%$ L-glutamine (Invitrogen, San Diego, CA), $1.5 \mu \mathrm{g} / \mathrm{ml}$ cytosine 1-d-arabinofuranoside (ARA-C, from Sigma), as described previously [20] [30]. In order to obtain cultures of peripheral glia, cells from dissociated DRGs were plated onto flasks in a medium similar to the one described above but without ARA-C, nonneuronal cells were allowed to reproduce. Medium was changed bi-weekly. By the time confluence was reached (about 2 weeks) all neuronal cells had died off. Cells were then splitted onto Petri dishes for patch clamp recordings, calcium imaging, or mRNA extraction. 


\subsection{Solutions and Chemicals}

Salts and other chemicals were of the highest purity grade (Sigma, Milan, Italy). For electrophysiological and calcium imaging experiments the standard extracellular saline was (mM) $140 \mathrm{NaCl}, 4 \mathrm{KCl}, 2 \mathrm{MgCl}_{2}, 2 \mathrm{CaCl}_{2}, 10$ HEPES, 5 glucose, buffered to $\mathrm{pH} 7.4$ with $\mathrm{NaOH}$ and osmolarity adjusted to $\sim 315 \mathrm{mOsm}$ with mannitol. The calcium-free extracellular saline was prepared by removing $\mathrm{CaCl}_{2}$ salt and adding $0.5 \mathrm{mM}$ EGTA in patch clamp experiments, and $5 \mathrm{mM}$ EGTA in calcium imaging experiments. It can be calculated that $0.5 \mathrm{mM}$ EGTA, even considering a $0.1 \mathrm{mM}$ contamination of calcium from other salts, is sufficient to clamp free calcium in the extracellular solution to a level similar to intracellular resting calcium in astrocytes [31]. The patch pipette (intracellular) solution was composed of (mM): $144 \mathrm{KCl}, 2 \mathrm{MgCl}_{2}, 5$ EGTA, 10 HEPES, pH 7.2 with $\mathrm{KOH}$, and osmolarity adjusted at $\sim 300 \mathrm{mOsm}$ with mannitol. Osmolality was measured with a vapor-pressure osmometer (Wescor 5500, Delcon, Italy). For patch clamp, the different solutions containing the pharmacological agents were applied with a gravity-driven, local perfusion system at a flow rate of $\sim 200 \mu \mathrm{l} / \mathrm{min}$ positioned within $\sim 200 \mu \mathrm{m}$ of the recorded cell. Solution changes during calcium imaging experiments were performed with an automated fast application system (CV Scientific, Modena, Italy) or manually. AITC was dissolved in the extracellular solution while sonicating to aid dispersal, and fresh solution prepared every 2 hours.

\subsection{Calcium Imaging}

Calcium imaging was performed with protocols similar to those described in previous work [19] [20] [30]. In brief, cultured cells were plated on poly-L-lysine-coated glass coverslips, then loaded with the calcium dye Fluo-4 AM (10 $\mu \mathrm{M}$; Invitrogen). Coverslips were imaged with an EMCCD camera-based system (Andor Technology, Belfast, $\mathrm{UK}$ ) in a solution of the following composition: $140 \mathrm{mM} \mathrm{NaCl}, 1.8 \mathrm{mM} \mathrm{CaCl}_{2}, 1 \mathrm{mM}$ $\mathrm{MgCl}_{2}, 4 \mathrm{mM} \mathrm{KCl}, 10 \mathrm{mM}$ HEPES, $4 \mathrm{mM}$ glucose, $\mathrm{pH}$ 7.4. High numerical aperture 10x objective was used throughout. At the end of the experiment, the maximal fluorescence (Fmax) was measured with a saturation concentration of ionomycin $(10 \mu \mathrm{M}$; Calbiochem, La Jolla, CA) in the presence of $\mathrm{Ca}^{2+}(30 \mathrm{mM})$ and $\mathrm{K}^{+}(125 \mathrm{mM})$. Data are expressed as $\triangle \mathrm{F} / \mathrm{Fmax}$. All experiments were performed at $20^{\circ} \mathrm{C}-22^{\circ} \mathrm{C}(\mathrm{RT})$. Solutions were applied with an automated fast perfusion system (CV Scientific, Modena, Italy).

\subsection{Electrophysiology}

Current recordings were obtained with the whole-cell configuration of the patch clamp technique as previously described [29]. Patch pipettes were prepared from thin-walled borosilicate glass capillaries to obtain a tip resistance of $2-4 \mathrm{M} \Omega$ when filled with the standard internal solution (see above). Membrane currents were amplified (amplifier List EPC-7, Darmstadt, Germany), filtered at $2 \mathrm{kHz}(-3 \mathrm{~dB})$ and acquired at a sample rate of $5 \mathrm{kHz}$ on a microcomputer for off-line analysis (pClamp 6, Axon Instrument, Foster City, CA, USA and Origin 6.0, MicroCal, Northhampton, MA, USA). Because of the large amplitude of the currents often measured, the access resistance (below 10 
$\mathrm{M} \Omega$ ) was corrected for to $60 \%-80 \%$. Reference electrode was an agar bridge filled with $150 \mathrm{mM} \mathrm{NaCl}$. Experiments were carried out at $20^{\circ} \mathrm{C}-24^{\circ} \mathrm{C}$. Current densities were calculated by dividing the current values measured at each membrane potential by the cell capacitance derived from the correction of the capacitive transients of the recorded cells by means of the analogical circuit of the patch-clamp amplifier.

\subsection{Transient Expression of TRPA1 Channel}

DITNC-1 cells, an astrocyte derived cell line [32], were cultured in DMEM supplemented with $10 \%$ FBS, non essential amino acid cocktail $(0.1 \mathrm{mM})$, penicillin $(50 \mathrm{U} / \mathrm{ml})$ and streptomycin $(50 \mu \mathrm{g} / \mathrm{ml})$, grown in $100-\mathrm{mm}$ Petri dishes and maintained in a humidified-atmosphere incubator at $37^{\circ} \mathrm{C}$ with $5 \% \mathrm{CO}_{2}$.

As a control experiment, DITNC-1 cells were co-transfected with the TRPA1 clone and the plasmid encoding the reporter gene EYFP (pEYFP). Briefly, the day before transfection, cells were re-plated in 35-mm Petri dishes at a density of $2-5 \times 104$ per dish and maintained in supplemented DMEM. Cells were co-transfected with the two plasmids by use of Lipofectamine 2000, following the manufacturer's instructions (Invitrogen, San Diego, CA). All experiments were performed after $48 \mathrm{~h}$ from transfection.

\subsection{Statistical Analysis}

Currents elicited with families of voltage steps or voltage ramps were analyzed with Clampfit of pClamp 6 suite (Axon Instruments, Foster City, CA, USA) and Origin (Microcal, Northampton, MA, USA). Data are expressed as mean \pm standard error (SE) of several cells ( $\mathrm{n}$ ) in the different conditions. Because of possible differences in cell size, membrane currents have been normalized and are shown as current densities. The statistical evaluation was performed with ANOVA followed by Bonferroni's posthoc test appropriate and a $\mathrm{p}$ value $<0.05$ was taken as statistically significant.

\subsection{Preparation of cDNA and Real Time PCR}

Total RNA was isolated using QIAgen RNAeasy minikit (QIAgen, Hilden, Germany), following instructions provided by the manufacturer. RNA was eluted in a final volume of $50 \mu \mathrm{l}$ of sterile water and stored at $-80^{\circ} \mathrm{C}$. cDNA was prepared from total RNA using Superscript III Reverse Transcriptase (Gibco-BRL, Rockville, MD,USA) according to manufacturer's instructions, in a final volume of $25 \mu \mathrm{l}$, with random hexamers as primers. At the end of the reverse transcription CDNA was diluted 1:2, and used for real time PCR.

Real time PCR was performed using UDG Glicosylase Invitrogen Supermix, following manufacturer's instructions, in a iQ5 real time PCR detector (Biorad Laboratories, Hercules, CA, USA). Primers for TRPA1 were TRPA1Dir (5'-GTGGATCAGAGGTCCACCAT-3') and TRPA1Rev (5'-TGGTGCTTCTTGTCGTGTTT-3'). SYBR green was used as fluorescent detector. Reactions, always performed in triplicate, were carried out for $45 \mathrm{cycles}$, each cycle consisting of $10 \mathrm{sec}$ at $94^{\circ} \mathrm{C}$ and $30^{\circ} \mathrm{sec}$ at $60^{\circ} \mathrm{C}$. At the end of the reactions melt curve analysis was always performed to detect possible aspecific 
amplification. Data were normalized to GAPDH expression, used as a housekeeping gene. GAPDH was quantified using a SYBR green as fluorescent detector, with primers GAPDHDir (5'-TCCATCCTCCACTAATCCACCTAA-3') and GAPDHrev (5'-CAGCACCTAGCACCCATGATC-3'). Relative expression of TRPA1 in astrocytes, was calculated with the "deltadelta cycle" method on the basis of the difference in the threshold cycle of TRPA1 and GAPDH, setting expression level of control sample as 1. Expression levels of DITNC-1, astrocytes and peripheral glial cells were therefore normalised to the value measured in DRG.

\section{Discussion}

The neonatal rat cultured astrocytes that we employed in this paper are normally considered a reliable model for the study of physiological functions of mammalian astrocytes. In culture, as in vivo, they express several functional TRP channels in the plasma membrane, with increasing evidence of the several, important roles that they play in astrocyte physiology [33] [34] [35].

In this paper we demonstrated the functional expression of TRPA1 channels in $\mathrm{Ca}^{2+}$-containing intracellular organelles in rat cortical astrocytes, with no expression in the plasma membrane. Furthermore, we demonstrate the absence of TRPA1 in cultured peripheral glial cells (satellite glial cells and Schwann cells), and in the largely used glial cell line DI TNC1. Our data also lead to the conclusion that non-neuronal cells in our DRG cultures are not contaminated by fibroblasts, which on the contrary express high levels of functional TRPA1: this channel, originally called P120 and ANKTM1, was originally detected in human cultured fibroblasts [4] [36].

AITC-activated responses measured both with $\mathrm{Ca}^{2+}$ imaging and with patch clamp [37] are totally absent in peripheral glial cells and in DI TNC1 glial cell line. This provides good evidence that the high concentration of AITC that we applied did not produce any non-specific effects on the plasma membranes, or on the internal organelles. Absence of TRPA1 in these cells is also ruled out by the complete absence of any mRNA specific for this channel. On the contrary, although low, the level of expression of TRPA 1 mRNA detected in astrocytes is sufficient to justify protein expression, and it is not artifactual: if a contamination of TRPA1-expressing cells such as fibroblast occurred, it would have more likely occurred in peripheral, rather than in central glia preparations. Moreover the cells responding to AITC with calcium signals had typical astrocyte morphology, and were stained by the GFAP monoclonal antibody (see Methods), so we can rule out any contamination from fibroblasts or other glial cells.

The outward current that we measured in response to AITC is consistent with $\mathrm{Ca}^{2+}$ activated potassium currents, which are ubiquitous, and largely present in astrocytes [38]. It is difficult to speculate the subtype of calcium-activated potassium channel(s) that may be responsible for the current measured, as the AITC treatment will likely cause a very large intracellular calcium increase, which would activate most calciumactivated channels, even at low voltages, as it is in our case. The fact that not every astrocyte responded to AITC with an outward current, the slowly-dev eloping and re- 
versible nature of this current (with a time course similar to calcium changes produced by AITC, and its presence even in the absence of extracellular calcium, rules out any possible non-specific effect of AICT on potassium currents. The transient nature of AITC effect supports the notion that the outward current is caused by calcium released intracellularly from stores via TRPA1, followed by calcium depletion, causing the decrease of current. In rat cortical astrocytes we could not see any voltage-activated calcium entry in imaging experiments where depolarization was induced with increased extracellular potassium (not shown), and the lack of voltage-activated calcium entry is also ruled out by patch clamp experiments in 0 extracellular calcium (see Figure 4). This experiment also further demonstrates the absence of functional TRPA1 channels in the membrane: TRPA1 current in several cell types displays outward rectification dependent on extracellular calcium, caused by channel partial blockage by calcium at membrane potentials negative to Erev [8]. However, we did not observe any difference between experiments with or without extracellular calcium.

Intracellular localization deep inside the cell is likely responsible for the low apparent affinity to AITC reported by our dose-response curve obtained with $\mathrm{Ca}^{2+}$ imaging (Figure 1). Plasma membrane and intracellular environment in fact may cause significant buffering of AITC and possibly of other endogenous activators, because of their chemical reactivity. Buffering of AITC by cytoplasm may contribute an explanation for the steep dose-response curve measured: cytoplasm may buffer AITC at low to mid concentrations, and then saturate at higher concentrations, therefore producing a steep rise towards the right of the curve.

The exact physiological or pathophysiological role of TRPA1 channels expressed intracellularly but not in the plasma membrane in rat cortical astrocytes is difficult to demonstrate based on our data. However, as it is well-accepted that TRPA1 functions as a chemosensor [16], intracellular TRPA1 would likely respond to a number of membrane permeant factors that may become present in the brain in a variety of conditions. Acrolein, an electrophilic TRPA1 agonist, not only is present in very high amounts in tobacco smoke and in other fumes and is produced as a toxic catabolite of chemotherapy agents [39], but it is also endogenously produced during oxidative stress, and its production is relevant in diseases such as multiple sclerosis [40]-[42]. Hydrogen sulfide $\left(\mathrm{H}_{2} \mathrm{~S}\right)$-derived polysulfides are also produced in the brain, where they activate TRPA1 in hippocampal astrocytes [43]. Also a role of TRPA1 as an oxygen-sensing mechanism cannot be ruled out in cortical astrocytes [44], as oxygen readily permeates the membrane, and an intracellular sensor would be able to produce a cellular response via calcium signals, while simultaneously avoiding changes in membrane potential.

It has been reported that also bacterial lipopolysaccharides (LPS) directly activate TRPA1 [45]. LPS may reach astrocytes during vascular damages or even when the blood-brain barrier is intact, although in small amounts [46], but LPS is probably unlikely to reach TRPA1 in cells that express it only intracellularly.

Further work will be necessary to demonstrate whether the absence of proximity/contact with neurons or the absence of a specific growth factor in the culture me- 
dium is the reason for the lack of expression of TRPA1 in the membrane in rat cortical astrocytes, or if relegation of TRPA1 to organelles is a specific physiological localization in these cells, differently from the proposed physiological localization in other areas: intracellular localization may be necessary to differentiate the function of TRPA1 in cortical astrocytes (allowing them to respond only to high levels of agonists) from the function of TRPA1 expressed in the plasma membrane in astrocytes in the hippocampus [13] [14] where TRPA1 mediates different, more physiological rather than pathophysiological functions.

\section{Conclusion}

In conclusion, our data suggest a role of TRPA1 in central but not in peripheral nervous system mechanisms mediated by glia.

\section{Acknowledgements}

We are grateful to Prof. Stefano Ferroni for constructive feedback in functional experiments. This work was supported by grants from Fondazione Cassa di Risparmio di Modena and Fondazione Cassa di Risparmio di Carpi (Italy) to V.V., and by University of Bologna (grant RFO2011) and Bando Progetti di Ricerca Finalizzata IRCCS - Istituto delle Scienze Neurologiche di Bologna, Italy, (2010 RF-2010-2313899) to M.C.

\section{References}

[1] Clapham, D.E., Julius, D., Montell, C. and Schultz, G. (2005) International Union of Pharmacology. XLIX. Nomenclature and Structure-Function Relationships of Transient Receptor Potential Channels. Pharmacological Reviews, 57, 427-450.

http://dx.doi.org/10.1124/pr.57.4.6

[2] Montell, C., Birnbaumer, L., Flockerzi, V., Bindels, R.J., Brudorf, E.A., Caterina, M.J., Clapham, D.E., Harteneck, C., Heller, S., Julius, D., Kojima, I., Mori, Y., Penner, R., Prawitt, D., Scharenberg, A.M., Schultz, G., Shimizu, N. and Zhu, M.X. (2002) A Unified Nomenclature for the Superfamily of TRP Cation Channels. Molecular Cell, 9, 229-231. http://dx.doi.org/10.1016/S1097-2765(02)00448-3

[3] Garcia-Anoveros, J. and Nagata, K. (2007) TRPA1. Handbook of Experimental Pharmacology, 347-362. http://dx.doi.org/10.1007/978-3-540-34891-7_21

[4] Jaquemar, D., Schenker, T. and Trueb, B. (1999) An Ankyrin-Like Protein with Transmembrane Domains Is Specifically Lost after Oncogenic Transformation of Human Fibroblasts. Journal of Biological Chemistry, 274, 7325-7333.

http://dx.doi.org/10.1074/jbc.274.11.7325

[5] Story, G.M., Peier, A.M., Reeve, A.J., Eid, S.R., Mosbacher, J., Hricik, T.R., Earley, T.J., Hergarden, A.C., Andersson, D.A., Hwang, S.W., McIntyre, P., Jegla, T., Bevan, S. and Patapoutian, A. (2003) ANKTM1, a TRP-Like Channel Expressed in Nociceptive Neurons, Is Activated by Cold Temperatures. Cell, 112, 819-829. http://dx.doi.org/10.1016/S0092-8674(03)00158-2

[6] De Petrocellis, L., Vellani, V., Schiano-Moriello, A., Marini, P., Magherini, P.C., Orlando, P. and Di Marzo, V. (2008) Plant-Derived Cannabinoids Modulate the Activity of Transient Receptor Potential Channels of Ankyrin Type-1 and Melastatin Type-8. Journal of Pharmacology and Experimental Therapeutics, 325, 1007-1015. 
http://dx.doi.org/10.1124/jpet.107.134809

[7] Anand, U., Otto, W.R., Facer, P., Zebda, N., Selmer, I., Gunthorpe, M.J., Chessell, I.P., Sinisi, M., Birch, R. and Anand, P.(2008) TRPA1 Receptor Localisation in the Human Peripheral Nervous System and Functional Studies in Cultured Human and Rat Sensory Neurons. Neuroscience Letters 438, 221-227. http://dx.doi.org/10.1016/j.neulet.2008.04.007

[8] Salas, M.M., Hargreaves, K.M. and Akopian, A.N. (2009) TRPA1-Mediated Responses in Trigeminal Sensory Neurons: Interaction between TRPA1 and TRPV1. European Journal of Neuroscience, 29, 1568-1578. http://dx.doi.org/10.1111/j.1460-9568.2009.06702.x

[9] Hinman, A., Chuang, H.H., Bautista, D.M. and Julius, D. (2006) TRP Channel Activation by Reversible Covalent Modification. Proceedings of the National Academy of Sciences United States of America, 103, 19564-19568. http://dx.doi.org/10.1073/pnas.0609598103

[10] Macpherson, L.J., Dubin, A.E., Evans, M.J., Marr, F., Schultz, P.G., Cravatt, B.F. and Patapoutian, A. (2007) Noxious Compounds Activate TRPA1 Ion Channels through Covalent Modification of Cysteines. Nature, 445, 541-545. http://dx.doi.org/10.1038/nature05544

[11] Brone, B., Peeters, P.J., Marrannes, R., Mercken, M., Nuydens, R., Meert, T. and Gijsen, H.J.M. (2008) Tear Gasses CN, CR, and CS Are Potent Activators of the Human TRPA1 Receptor. Toxicology and Applied Pharmacology, 231, 150-156. http://dx.doi.org/10.1016/j.taap.2008.04.005

[12] Kunert-Keil, C., Bisping, F., Kruger, J. and Brinkmeier, H. (2006) Tissue-Specific Expression of TRP Channel Genes in the Mouse and Its Variation in Three Different Mouse Strains. Bmc Genomics, 7, 1597. http://dx.doi.org/10.1186/1471-2164-7-159

[13] Shigetomi, E., Jackson-Weaver, O., Huckstepp, R.T., O'Dell, T.J. and Khakh, B.S. (2013) TRPA1 Channels Are Regulators of Astrocyte Basal Calcium Levels and Long-Term Potentiation via Constitutive D-Serine Release. Journal of Neuroscience, 33, 10143-10153. http://dx.doi.org/10.1523/JNEUROSCI.5779-12.2013

[14] Shigetomi, E., Tong, X.P., Kwan, K.Y., Corey, D.P. and Khakh, B.S. (2012) TRPA1 Channels Regulate Astrocyte Resting Calcium and Inhibitory Synapse Efficacy Through GAT-3. Nature Neuroscience, 15, 70-80. http://dx.doi.org/10.1038/nn.3000

[15] Lee, S.M., Cho, Y.S., Kim, T.F., Jin, M.U., Ahn, D.K., Noguchi, K. and Bae, Y.C. (2012) An Ultrastructural Evidence for the Expression of Transient Receptor Potential Ankyrin 1 (TRPA1) in Astrocytes in the Rat Trigeminal Caudal Nucleus. Journal of Chemical Neuroanatomy, 45, 45-49. http://dx.doi.org/10.1016/j.jchemneu.2012.07.003

[16] Nilius, B., Appendino, G. and Owsianik, G. (2012) The Transient Receptor Potential Channel TRPA1: From Gene to Pathophysiology. Pflugers Archiv-European Journal of Physiology, 464, 425-458. http://dx.doi.org/10.1007/s00424-012-1158-Z

[17] Tai, C., Zhu, S. and Zhou, N. (2008) TRPA1: The Central Molecule for Chemical Sensing in Pain Pathway? Journal of Neuroscience, 28, 1019-1021. http://dx.doi.org/10.1523/JNEUROSCI.5237-07.2008

[18] Radany, E.H., Brenner, M., Besnard, F., Bigornia, V., Bishop, J.M. and Deschepper, C.F. (1992) Directed Establishment of Rat Brain Cell Lines with the Phenotypic Characteristics of Type 1 Astrocytes. Proceedings of the National Academy of Sciences United States of America, 89, 6467-6471. http://dx.doi.org/10.1073/pnas.89.14.6467

[19] Vellani, V., Colucci, M., Lattanzi, R., Giannini, E., Negri, L., Melchiorri, P. and McNaughton, P.A. (2006) Sensitization of Transient Receptor Potential Vanilloid 1 by the Prokineticin Receptor Agonist Bv8. Journal of Neuroscience, 26, 5109-5116. http://dx.doi.org/10.1523/JNEUROSCI.3870-05.2006

[20] Vellani, V., Prandini, M., Giacomoni, C., Pavesi, G., Ravegnani, L., and Magherini, P.C. 
(2011) Functional Endothelin Receptors Are Selectively Expressed in Isolectin B4-Negative Sensory Neurons and Are Upregulated in Isolectin B4-Positive Neurons by Neurturin and Glia-Derived Neurotropic Factor. Brain Research, 1381, 31-37.

http://dx.doi.org/10.1016/j.brainres.2011.01.019

[21] Ferroni, S., Nobile, M., Caprini, M. and Rapisarda, C. (2000) pH Modulation of an Inward Rectifier Chloride Current in Cultured Rat Cortical Astrocytes. Neuroscience, 100, 431-438. http://dx.doi.org/10.1016/S0306-4522(00)00272-4

[22] Fajardo, O., Meseguer, V., Belmonte, C. and Viana, F. (2008) TRPA1 Channels: Novel Targets of 1,4-Dihydropyridines. Channels (Austin), 2, 429-438.

http://www.ncbi.nlm.nih.gov/pubmed/18971630 http://dx.doi.org/10.4161/chan.2.6.7126

[23] Doerner, J.F., Gisselmann, G., Hatt, H. and Wetzel, C.H. (2007) Transient Receptor Potential Channel A1 Is Directly Gated by Calcium Ions. The Journal of Biological Chemistry, 282, 13180-13189. http://dx.doi.org/10.1074/jbc.M607849200

[24] Wang, Y.Y., Chang, R.B., Waters, H.N., McKemy, D.D. and Liman, E.R. (2008) The Nociceptor Ion Channel TRPA1 Is Potentiated and Inactivated by Permeating Calcium Ions. The Journal of Biological Chemistry, 283, 32691-32703. http://dx.doi.org/10.1074/jbc.M803568200

[25] Zurborg, S., Yurgionas, B., Jira, J.A., Caspani, O. and Heppenstall, P.A. (2007) Direct Activation of the Ion Channel TRPA1 by $\mathrm{Ca}^{2+}$. Nature Neuroscience, 10, 277-279. http://dx.doi.org/10.1038/nn1843

[26] MacVicar, B.A. (1984) Voltage-Dependent Calcium Channels in Glial-Cells. Science, 226, 1345-1347. http://dx.doi.org/10.1126/science.6095454

[27] Duffy, S. and MacVicar, B.A. (1994) Potassium-Dependent Calcium Influx in Acutely Isolated Hippocampal Astrocytes. Neuroscience, 61, 51-61. http://dx.doi.org/10.1016/0306-4522(94)90059-0

[28] Carmignoto, G., Pasti, L. and Pozzan, T. (1998) On the Role of Voltage-Dependent Calcium Channels in Calcium Signaling of Astrocytes in Situ. The Journal of Neuroscience, 18, 4637-4645. http://www.ncbi.nlm.nih.gov/pubmed/9614238

[29] Ferroni, S., Marchini, C., Schubert, P. and Rapisarda, C. (1995) Two Distinct Inwardly Rectifying Conductances Are Expressed in Long-Term Dibutyryl-Cyclic-AMP Treated Rat Cultured Cortical Astrocytes. FEBS Letters, 367, 319-325. http://dx.doi.org/10.1016/0014-5793(95)00588-Z

[30] Vellani, V., Kinsey, A.M., Prandini, M., Hechtfischer, S.C., Reeh, P., Magherini, P.C., Giacomoni, C. and McNaughton, P.A. (2010) Protease Activated Receptors 1 and 4 Sensitize TRPV1 in Nociceptive Neurones. Molecular Pain, 6, 61.

[31] Schoenmakers, T.J., Visser, G.J., Flik, G. and Theuvenet, A.P. (1992) CHELATOR: An Improved Method for Computing Metal Ion Concentrations in Physiological Solutions. Biotechniques, 12, 870-879. http://www.ncbi.nlm.nih.gov/pubmed/1642895

[32] Cameron, P.L., Liu, C.D., Smart, D.K., Hantus, S.T., Fick, J.R. and Cameron, R.S. (2002) Caveolin-1 Expression Is Maintained in Rat and Human Astroglioma Cell Lines. Glia, 37, 275-290. http://dx.doi.org/10.1002/glia.10036

[33] Benfenati, V., Amiry-Moghaddam, M., Caprini, M., Mylonakou, M.N., Rapisarda, C., Ottersen, O.P. and Ferroni, S. (2007) Expression and Functional Characterization of Transient Receptor Potential Vanilloid-Related Channel 4 (TRPV4) in Rat Cortical Astrocytes. Neuroscience, 148, 876-892. http://dx.doi.org/10.1016/j.neuroscience.2007.06.039

[34] Verkhratsky, A., Reyes, R.C. and Parpura, V. (2014) TRP Channels Coordinate Ion Signal- 
ling in Astroglia. In: Nilius, B., Gudermann, T., Jahn, R., Lill, R., Offermanns, S. and Petersen, O.H., Eds., Reviews of Physiology, Biochemistry and Pharmacology 166, Springer International Publishing, Berlin, Heidelberg, 1-22. http://dx.doi.org/10.1007/112_2013_15

[35] Scimemi, A. (2013) A TRP among the Astrocytes. The Journal of Physiology, 591, 9-15. http://dx.doi.org/10.1113/jphysiol.2012.237883

[36] Schenker, T. and Trueb, B. (1998) Down-Regulated Proteins of Mesenchymal Tumor Cells. Experimental Cell Research, 239, 161-168. http://dx.doi.org/10.1006/excr.1997.3896

[37] Baker, M.D. (2002) Electrophysiology of Mammalian Schwann Cells. Progress in Biophysics and Molecular Biology, 78, 83-103. http://dx.doi.org/10.1016/S0079-6107(02)00007-X

[38] Quandt, F.N. and MacVicar, B.A. (1096) Calcium Activated Potassium Channels in Cultured Astrocytes. Neuroscience, 19, 29-41. http://dx.doi.org/10.1016/0306-4522(86)90003-5

[39] Bautista, D.M., Jordt, S.E., Nikai, T., Tsuruda, P.R., Read, A.J., Poblete, J., Yamoah, E.N., Basbaum, A.I. and Julius, D. (2006) TRPA1 Mediates the Inflammatory Actions of Environmental Irritants and Proalgesic Agents. Cell, 124, 1269-1282. http://dx.doi.org/10.1016/j.cell.2006.02.023

[40] Tully, M. and Shi, R.Y. (2013) New Insights in the Pathogenesis of Multiple Sclerosis-Role of Acrolein in Neuronal and Myelin Damage. International Journal of Molecular Sciences, 14, 20037-20047. http://dx.doi.org/10.3390/ijms141020037

[41] Shi, R.Y., Rickett, T. and Sun, W.J. (2011) Acrolein-Mediated Injury in Nervous System Trauma and Diseases. Molecular Nutrition \& Food Research, 55, 1320-1331. http://dx.doi.org/10.1002/mnfr.201100217

[42] Shi, Y.Z., Sun, W.J., McBride, J.J., Cheng, J.X. and Shi, R.Y. (2011) Acrolein Induces Myelin Damage in Mammalian Spinal Cord. Journal of Neurochemistry, 117, 554-564. http://dx.doi.org/10.1111/j.1471-4159.2011.07226.x

[43] Kimura, Y., Mikami, Y., Osumi, K., Tsugane, M., Oka, J. and Kimura, H. (2013) Polysulfides Are Possible $\mathrm{H}_{2} \mathrm{~S}$-Derived Signaling Molecules in Rat Brain. The FASEB Journal, 27, 2451-2457. http://dx.doi.org/10.1096/fj.12-226415

[44] Takahashi, N., Kuwaki, T., Kiyonaka, S., Numata, T., Kozai, D., Mizuno, Y., Yamamoto, S., Naito, S., Knevels, E., Carmeliet, P., Oga, T., Kaneko, S., Suga, S., Nokami, T., Yoshida, J. and Mori, Y. (2011) TRPA1 Underlies a Sensing Mechanism for $\mathrm{O}_{2}$. Nature Chemical Biology, 7, 701-711. http://dx.doi.org/10.1038/nchembio.640

[45] Meseguer, V., Alpizar, Y.A., Luis, E., Tajada, S., Denlinger, B., Fajardo, O., Manenschijn, J.A., Fernandez-Pena, C., Talavera, A., Kichko, T., Navia, B., Sanchez, A., Senaris, R., Reeh, P., Perez-Garcia, M.T., Lopez-Lopez, J.R., Voets, T., Belmonte, C., Talavera, K. and Viana, F. (2014) TRPA1 Channels Mediate Acute Neurogenic Inflammation and Pain Produced by Bacterial Endotoxins. Nature Communications, 5, Article No. 3125. http://dx.doi.org/10.1038/ncomms4125

[46] Banks, W.A. and Robinson, S.M. (1995) Minimal Penetration of Lipopolysaccharide across the Murine Blood-Brain Barrier. Brain Behavior and Immunity, 24, 102-109. http://dx.doi.org/10.1016/j.bbi.2009.09.001 
Submit or recommend next manuscript to SCIRP and we will provide best service for you:

Accepting pre-submission inquiries through Email, Facebook, LinkedIn, Twitter, etc. A wide selection of journals (inclusive of 9 subjects, more than 200 journals)

Providing 24-hour high-quality service

User-friendly online submission system

Fair and swift peer-review system

Efficient typesetting and proofreading procedure

Display of the result of downloads and visits, as well as the number of cited articles

Maximum dissemination of your research work

Submit your manuscript at: http://papersubmission.scirp.org/

Or contact jbise@scirp.org 